


\title{
LITERATURA Y CIENCIAS SOCIALES
}

\author{
LITERATURE AND SOCIAL SCIENCES
}

Felipe Arocena*

\section{Resumen}

La literatura y la ciencia marcaron dos modelos de conocimiento alternativos entre los que se estableció una suerte de disputa de competencias sobre sus respectivas idoneidades, a fin de entender el nuevo contexto social que nacía con el siglo XIX europeo. En este artículo se analiza cómo precisamente el espacio de intersección entre ambos discursos, entre "las dos culturas", es especialmente creativo para las ciencias sociales. En particular, la sociología se movió entre la inspiración en un modelo de narración literaria y la influencia del discurso sobre la verdad proveniente de las ciencias naturales.

\section{Palabras clave}

Literatura y sociedad, ciencias, sociología, discurso, verdad.

\begin{abstract}
Literature and Science demarcated two alternative knowledge models, which disputed their capacity to better understand the new social context that was born in the $\mathrm{XIX}^{\text {th }}$ century. This work analyzes how that space in between the two discourses, between "the two cultures", is extraordinarily creative for social sciences. In particular, sociology moved between the inspiration drawn from the model of literary narrative and the influence of the discourse about truth from the natural sciences.
\end{abstract}

* Sociólogo uruguayo, Doctor en Ciencias Sociales de la Universidad Cándido Mendes (Instituto Universitario de Pesquisas de Río de Janeiro). Sus intereses incluyen historia y sociedad en América Latina, globalización e identidad, sociología de la cultura y opinión pública. Sus investigaciones atienden el análisis de la globalización ante la resistencia de culturas locales; igualmente se ha preocupado por buscar posibilidades en el desarrollo sustentable en América Latina. Ha sido profesor visitante en la Universidad de Mar del Plata (2005), Georgia Institute of Technology, Atlanta (2001-2003; 2005 y 2006), Dartmouth College, Hanover (2005 y 2007), Universidad Federal de Río de Janeiro (2000). En 2001 ganó el Premio Anual de Literatura de Uruguay (Categoría Ensayo Literario). 


\section{Keywords}

Literature and society, science, sociology, discourse, truth.

\section{Introducción}

En un breve pero penetrante párrafo, Kant (1784) sintetizaba lo que para él era la Ilustración:

La Ilustración, escribió, es la liberación del hombre de su culpable incapacidad. La incapacidad significa la imposibilidad de servirse de su inteligencia sin la guía de otro. Esta incapacidad es culpable porque su causa no reside en la falta de inteligencia sino de decisión y valor para servirse por sí mismo de ella sin la tutela de otro. ;Atrévete a saber! (sapere aude) ¡Ten el valor de servirte de tu propia razón!: he aquí el lema de la Ilustración (citado en Cassirer, 1950: 186).

Como contraposición al sesgo iluminista en la capacidad del conocimiento racional para descubrir las estructuras y leyes universales que rigen el mundo de los objetos, de la naturaleza y de los hombres -y al que Kant también se esforzó por ponerle límites-, en el Romanticismo, dialécticamente, se intentó realzar lo que había pasado a situarse en el lado oscuro de la luna. Por esta razón,

el acento se desplazó hacia la autenticidad de las emociones expresadas $\mathrm{y}$, en consecuencia, hacia la sinceridad e integridad del artista. Se llegó así a admitir que la espontaneidad, la individualidad y la "verdad interior" eran los criterios aplicables al enjuiciamiento de cualquier obra artística, literaria o musical de cualquier época y país [...] iAtrévete a sentir!, ¡Ten el valor de seguir tu propia intuición!, fue el lema de los románticos (Honour, 1981: 20, 202).

Atrévete a saber o atrévete a sentir: la oposición que, con propósito provocativo, me sirve de introducción refleja, a pesar de su simplicidad, para los distintos énfasis de ambos momentos históricos.

En este ir y venir entre las matrices ilustradas y románticas se origina la sociología, como tan claramente lo mostrara Robert Nisbet (1977), alimentada por el impacto que producen las dos revoluciones -industrial y política- sobre fines del siglo XVIII y comienzos del XIX; oscilando a través de una línea de equilibrio entre la comunidad perdida y la sociedad de masas que comenzaba a delinearse, entre la autoridad natural de las personas y el poder impersonal de las instituciones, entre el estatus singular y la emergencia de las clases sociales, entre la secularización de la ciencia y la necesidad de la trascendencia y del mito, y entre la confianza en el progreso y la alienación del nuevo mundo que se vislumbraba. En el intento por comprender y captar estos cambios se generaron discusiones filosóficas, epistemológicas y ontológicas profundas, que finalmente se materializaron en distintas perspectivas políticas. Los conservadores veían con desconfianza el nuevo orden que se superponía a los rasgos del pasado; los radicales proyectaban aceleradamente nuevas utopías; los liberales adoptaban como principal bandera profundizar las virtudes del capitalismo liberal en gestación, para superar sus carencias.

Esta verdadera dialéctica entre la Ilustración y el Romanticismo también tiene que ver con 
los distintos tipos de discursos empleados para representar la nueva realidad social. $\mathrm{La}$ literatura y la ciencia marcaron dos modelos de conocimiento alternativos entre las cuales se estableció una suerte de disputa de competencias sobre sus respectivas idoneidades para entender el nuevo contexto. En particular, la sociología se mueve entre la inspiración que encuentra en un modelo de narración literaria y la influencia que tiene el discurso sobre la verdad proveniente de las ciencias naturales.

En forma bastante convincente, Wolf Lepenies (1988), en su libro Entre la ciencia y la literatura: el surgimiento de la sociología, nos muestra cómo esta última se va conformando en ese espacio situado entre la literatura y la ciencia. Alternando entre el lenguaje científico de las ciencias naturales y la narrativa literaria, entre la racionalidad del método y el entendimiento de los sentimientos y la cultura, la sociología comienza a conquistar su espacio como disciplina. Lepenies identifica a la sociología como "la tercera cultura" y evalúa lo siguiente:

Su problema (no tanto el de la historia) es que, por más que intente imitar a las ciencias naturales, nunca podrá convertirse en una verdadera ciencia natural de la sociedad; pero por otro lado, si abandona su orientación científica se acerca peligrosamente a la literatura (1988: 7).

Efectivamente ese espacio intersticial entre la literatura y la ciencia que ocupó la sociología puede ejemplificarse en varios casos muy evidentes. Es muy conocida, por ejemplo, la importancia que Marx atribuyó a Balzac para entender a la aristocracia francesa, a la monarquía de Luis Felipe. De hecho, Balzac quería titular a su Comedia humana como Estudios sociales. Otro ejemplo que mencionaré es el de la relación entre Thomas Mann y
Max Weber, ambos complementándose para entender a ese personaje nuevo de la historia: el burgués protestante, calvinista y heroico. Está también la influencia del sociólogo sobre el escritor Kafka, quien no hubiera escrito El proceso sin los antecedentes weberianos sobre la burocracia y su impacto en el mundo que se estaba gestando. Y un último ejemplo, casi obligatorio, que tengo que mencionar es el de Walter Benjamín y su trabajo sobre el flaneur urbano y la modernidad, inspirándose en Baudelaire.

A pesar de estos ejemplos clásicos de las fructíferas relaciones entre las ciencias sociales y la literatura, uno no puede dejar de sorprenderse al ver cómo durante la mayor parte del siglo XX predominaron los antagonismos: escritores y científicos sociales parecen dos especies irreconciliables que se miran con recelo mutuo. Los primeros, dando la espalda a los arquetipos sistémicos, estructurales y excesivamente autosuficientes de los cientistas sociales asimilados a técnicos; los segundos, reduciendo la literatura o el ensayo social al terreno de las especulaciones no verificables, subjetivas y con pretensiones inaceptables de verdad.

Algo de este antagonismo se expresaba paradigmáticamente en la cultura inglesa a través de las figuras emblemáticas de Bentham y Coleridge. "En el siglo XIX todo inglés era o partidario de Bentham o de Coleridge; el primero preguntaba '¿esto es verdad ?', mientras el segundo interrogaba '¿Qué significa esto?'” (Lepenies, 1988: 104). En 1840, John Stuart Mill, refiriéndose precisamente a Bentham y Coleridge, escribió:

En realidad emplearon, por lo general, diferentes materiales; pero como los materiales de ambos eran observaciones reales, fruto auténtico de la experiencia, se descubrirá a la larga que los resultados no son 
antagónicos sino complementarios. Lo mismo puede decirse de sus métodos filosóficos: eran diferentes, pero ambos representaban procesos lógicos legítimos. En todo sentido, cada uno de ellos es la "contraparte complementaria" del otro; los puntos fuertes de uno corresponden a los puntos débiles del otro. Quienquiera que llegase a dominar las premisas y controlar los métodos de ambos sería poseedor de toda la filosofía inglesa de su época (citado en Barry, 1974: 17-18).

Era un optimista Mill ${ }^{1}$.

La identificación de la sociología con esa "tercera cultura" de la que habla Lepenies hace alusión al famoso libro de C.P. Snow publicado en 1959: Las dos culturas, que disparó una intensa discusión sobre ciencia y literatura y uno de cuyos frutos es el libro de Aldous Huxley que lleva justamente como título Literatura y Ciencia, publicado en 1963. Huxley caracterizaba a la primera así:

El mundo con el que lidia la literatura es el mundo en el que los seres humanos nacen, viven y finalmente mueren; el mundo en el que aman y odian, en el cual experimentan triunfos y humillaciones, esperanza y desazón; el mundo de sufrimientos y alegrías, de locura y sentido común, estupidez, astucia y sabiduría; el mundo de las presiones sociales e impulsos individuales, de la razón contra la pasión, de instintos

1 Más recientemente la misma oposición ha sido resaltada por Karl Popper, quien cree un tanto simplistamente que la filosofía deba ocuparse solamente de los problemas de verdad, pues la problemática del significado la considera “filosóficamente no importante" (1997: 28-43). y convenciones, de lenguaje compartido y sensaciones y emociones intransferibles. [El científico, en cambio,] es el habitante de un universo radicalmente diferente -no el universo de apariencias dadas, sino el mundo de la inferencia de refinadas estructuras, no el mundo experimentado de eventos únicos y cualidades diversas, sino el mundo de regularidades cuantificadas-". Huxley encontró una solución muy personal ante esta antinomia y proponía que los escritores se hicieran cargo de los descubrimientos científicos, poniéndoles "sangre y carne" y acercándolos al universo cotidiano o al "mundo de la vida" (Habermas, 1978: 8).

Debería ser todo esto suficiente para convencerles a ustedes de que las ciencias sociales y la literatura han tenido, como todo matrimonio que se precie, espacios de amor y odio, diálogos de sordos y conversaciones fructíferas, celos, recelos y admiración.

Siento necesidad de hacer una reflexión sobre la literatura y las ciencias sociales en nuestro contexto más inmediato del Río de la Plata y América Latina. En gran medida hay un paralelo importante en cómo aparece la ciencia social en nuestros países en relación con lo que ocurrió en el viejo continente. El ejemplo más diáfano es el de los ensayistas del siglo XIX y principios del XX, contra quienes posteriormente la sociología científica se encabrita para dar luz a las cátedras, primero en las facultades de derecho y bastante después conquistando su plena autonomía en las facultades de ciencias sociales o de filosofía. Es posible que este antagonismo entre los científicos sociales y los ensayistas, estos últimos vistos por los primeros como una variante del escritor o directamente como diletantes, haya sido necesario para 
el nacimiento de las disciplinas sociales como tal. Sin embargo, luego de todo el bagaje institucional y la reproducción de los saberes específicos de las diferentes ciencias sociales, les sugiero que piensen en los libros latinoamericanos más influyentes en este campo, independientemente de su tiempo histórico. Seguramente recordarán muchos, pero apostaría a que muy pocos de ustedes dejarían de incluir al Facundo del argentino Sarmiento, al Ariel de nuestro uruguayo Rodó, a Casa Grande y senzala del brasileño Gilberto Freyre o al Laberinto de la soledad del mexicano Octavio Paz. No es necesario destacar cuál es el común denominador que los recorre a todos ellos.

Más específicamente aquí, en mi pequeño país Uruguay, si tuviéramos que elegir entre las dos o tres figuras más importantes en el campo de las ciencias sociales, ¿a quiénes mencionaríamos? No creo que discrepen que Real de Azúa estaría en esa selección; él, ejemplo personificado de síntesis entre literatura y ciencias sociales, comenzó como profesor de literatura y se jubiló como cientista político; pero lo que lo hizo grande fue su apertura hacia la literatura y hacia la ciencia, su intento por comprender el significado de las cosas y por explicarlas causalmente. Con la distancia debida, se preguntó, como Coleridge: ¿qué significa esto?, y también como Bentham: ¿cuál es la verdad?

Parece existir hoy una preocupación compartida por algunos científicos sociales, críticos literarios, filósofos, ensayistas y ciudadanos que no cultivan estas artes en particular, por reconciliar caminos enfrentados durante demasiado tiempo. El impulso hermenéutico que ha tenido la ciencia social y el desarrollo de los llamados estudios culturales, así como la propia evolución de la epistemología científica admitiendo los límites de la certidumbre y las fronteras cada vez más borrosas de las disciplinas especializadas, han reabierto el camino para tratar más libremente muchos temas que requieren de una actitud complementaria entre la técnica y la especulación o la exploración. Tal vez esto sea simplemente consecuencia de un momento de incertidumbres frente a un mundo que continúa cambiando más rápidamente de lo que se puede comprender, y también es posible que contribuya de alguna manera a renovar el pensamiento social y a interesar a un público más amplio, cuyas preocupaciones parecen haber sido descuidadas por la sociología.

He intentado hacer esto en varios de mis propios trabajos, por ejemplo en el libro titulado De Quilmes a Hyde Park. Las fronteras culturales en la vida y la obra de William Henry Hudson (Arocena, 2000), autor, entre otra veintena de volúmenes, de La Tierra purpúrea, Allá lejos y hace tiempo y A pie por Inglaterra. Con cada uno de estos tres libros descubrió Uruguay, Argentina e Inglaterra para sus propios habitantes. La obra de Hudson y su propia vida se desarrollan precisamente nutriéndose de los antagonismos entre el Romanticismo y la Ilustración, recorren los conflictos teóricos que Nisbet describe con brillantez, y expresa esa oscilación entre la literatura y la ciencia como el caldo de cultivo en que surge la sociología, que Lepenies analizó para los casos alemán, francés e inglés.

Es que Hudson era mentalmente un romántico rezagado que practicaba sistemáticamente la ciencia natural a través de la botánica, la ornitología y sus ensayos especializados en revistas científicas. Reflexiona permanentemente sobre el nuevo mundo industrial de la gran ciudad que va superponiéndose al agrario de la pequeña comunidad. Y es, antes que nada, un escritor con un estilo personalísimo que se refleja en todos los géneros en que incursionó y que fue, con seguridad, la clave para su reconocimiento en Inglaterra como uno de los 
mejores escritores ingleses de fines del siglo pasado y comienzos del presente.

En este sentido, plantea Massingham:

La trinidad del sentimiento, el saber y la videncia -naturalista, artista, vidente entremezclados- rige en toda la obra de Hudson y es una de las razones por la cual fue tardíamente aceptado durante su vida, como gran escritor e intérprete. Rehuyó las corrientes definiciones del arte, de la ciencia, de la observación campestre, evitó propaganda y todas las actividades especializadas [...] porque ninguna de esas ropas confeccionadas para el maniquí le iban. Él rompió las costuras; era todo al mismo tiempo y no una cosa después de otra (1941: 79).

En este trabajo sobre Hudson, que para mi sorpresa fue aceptado para obtener el grado de Doctor en Sociología y luego fue premiado como ensayo literario, intenté situarme en las fronteras de esta disciplina, pues me parece necesario volver a ampliar el espectro de este campo de saber (en realidad, así procedieron varios de sus fundadores clásicos), a pesar de que ello pueda ir en desmedro de los propios intereses académicos creados y complique aún más la pregunta que no tiene una única respuesta de qué es y hace un sociólogo. Está claro que Hudson no era uno de ellos, pero tampoco quedan dudas que, entre varias cosas, también hizo sociología, en ocasiones explícitamente como lo demuestra cabalmente su fina investigación sobre los últimos coletazos del movimiento luddita en los alzamientos campesinos ingleses de 1830; la mayoría de las veces, es cierto, en forma implícita aunque logrando tal vez la mejor interpretación de la Banda Oriental del siglo XIX. Más importante que esta discusión un tanto estrecha es, sin embargo, que anali- zando el conjunto de su obra, inseparable en este caso de su propia vida, entendemos un poco más la sociedad en que estamos insertos $\mathrm{y}$, creo, podemos aprender a vivir un poco mejor en el mundo en que por destino o azar nos ha tocado caer.

\section{Referencias}

Arocena, F. (2000). De Quilmes a Hyde Park. Las fronteras culturales en la vida y la obra de William Henry Hudson. Montevideo: Editorial Banda Oriental.

Barry, B. (1974). Los sociólogos, los economistas y la democracia. Buenos Aires: Argentina.

Cassirer, E. (1950). Filosofía de la Ilustración. México: Fondo de Cultura Económica.

Habermas, J. (1968). Towards a Rational Society. Boston: Beacon Press.

Honour, H. (1981). El Romanticismo. Madrid: Alianza.

Kant, I. (1784/1988). Respuesta a la pregunta ¿qué es la Ilustración? Salamanca: Ediciones Universidad de Salamanca

Lepenies, W. (1988). Between Literature And Science: The Rise of Sociology. Cambridge: Cambridge University Press.

Massingham, J. (1941). Hudson, el gran primitivo. En Antología de Guillermo Enrique Hudson con estudios críticos sobre su vida y su obra (1941). Bueno Aires: Losada.

Nisbet, R. (1977). La formación del pensamiento sociológico. Buenos Aires: Amorrortu.

Popper, K. (1977). Búsqueda sin término. Una autobiografía intelectual. Madrid: Tecnos. 